\title{
Ética e Bioética no atendimento aos pacientes portadores de HIV/aids no Sistema Único de Saúde
}

Ethics and bioethics in the care of patients with HIVIAIDS in the Brazilian public health system (SUS)

\section{Hamilton Gomes Carneiro}

Aluno do Curso de Especialização em Direito Sanitário para membros do Ministério Público da União. Juiz de Direito da $2^{a}$ Vara Criminal da Comarca de Aparecida de Goiânia, Brasil.

Resumo: $O$ presente artigo tem como objetivo demonstrar a importância da humanização no atendimento ao paciente, analisando a integração entre as políticas nacionais de humanização (teoria) e os profissionais que atuam na atenção primária (prática), especialmente no trato aos pacientes portadores de HIV/aids, com enfoque na aplicação dos princípios da ética e bioética. Cuida-se de um tema relativamente novo na literatura. São abordadas, de forma sucinta, as principais características da Política Nacional de Humanização (PNH) do Sistema Único de Saúde (SUS), os fundamentos da ética e bioética e sua aplicação aos profissionais da saúde no trato com pacientes em geral, sobretudo naqueles portadores de HIV/aids. Trata-se de uma pesquisa do tipo revisão de literatura e estudo descritivo-qualitativo.

Palavras-chave: aids; humanização; bioética; SUS.

Keywords: AIDS; humanization; bioethics; SUS.

\section{Introdução}

O presente artigo tem como tema a ética e bioética no atendimento dos pacientes portadores do vírus da imunodeficiência humana (HIV) no Sistema Único de Saúde (SUS), especialmente no momento da conversa entre médico/paciente informando-o da infecção ${ }^{1}$, tendo como linha de pesquisa a ética sanitária.

\footnotetext{
1 O presente artigo baseia-se numa ação judicial ajuizada por uma doadora que foi ao banco de sangue e, após a primeira coleta, foi convidada a repetir o exame sob o pretexto de que a primeira amostra teria coagulado. No momento da entrega do resultado, a paciente afirma que foi destratada, pois nem lhe ofereceram a chance de se sentar ou tomar um café e o médico a acusou de assassina, por doar sangue sabendo que estava contaminado e poderia matar várias pessoas. Afirmou que foi
} 
Observa-se, no contexto mundial, um interesse em torno da humanização, relativo à organização da atenção à saúde e às necessidades do paciente. No entanto, os estudos têm dado pouca ênfase à relevância dessa temática nos atendimentos de atenção básica, onde o sujeito não é, muitas vezes, um cliente adoecido, mas que, da mesma forma, necessita e busca um atendimento de qualidade e humanizado.

Registra-se que o termo 'humanização' envolve o diálogo e a comunicação entre pacientes e profissionais, e também, o reconhecimento dos direitos do paciente. O ideal de humanização pode ser genericamente definido como um compromisso das tecnociências da saúde, em seus meios e fins, com a realização de valores contrafaticamente relacionados à felicidade humana e democraticamente validados como bem comum (Ayres, 2009).

Relacionando a Política Nacional de Humanização (PNH) do SUS com os portadores de HIV/aids, tem-se que a epidemia de aids tem gerado questionamentos éticos de diferentes ordens em todas as sociedades e culturas. A citada síndrome, ocasionada por um vírus cuja infecção ocorre primordialmente pela via sexual e sanguínea, colocou em questão valores e costumes diretamente relacionados às práticas sexuais, modos de vida e mitos referentes ao sangue. Foram necessárias duas décadas de respostas à epidemia para que se generalizasse a ideia de que um ambiente social discriminatório e preconceituoso, assim como modelos de intervenção que invadem a privacidade e os direitos das pessoas vivendo com HIV/aids, são contraproducentes para os programas de prevenção e assistência.

Depreende-se que, no Brasil, a PNH foi um marco divisor de águas nos serviços de saúde tanto no trabalho de prevenção e cura quanto de reabilitação. Até então, conhecia-se o modo correto de agir, mas a PNH ampliou o entendimento de gestores e profissionais da saúde quanto ao fato de que a humanização é sempre resultado do encontro entre seres humanos, de combinações entre diferenças e não de desigualdades (Brasil, 2004).

Assim, a aplicação dos princípios da ética e bioética à política de humanização do SUS mostra-se de basilar relevância, especialmente quando se trata de pacientes portadores de HIV, uma vez que os fundamentos trazidos pelo discurso ético residem em tomar a comunicação entre os sujeitos como uma práxis de reconhecimento mútuo, de descentração e partilhamento da compreensão acerca do bom e do justo; é meio hábil de tornar o processo de argumentação livre de coações, como capaz de construir e reconstruir discursos legitimamente reconhecidos ou válidos.

expulsa do local da doação sem maiores explicações. Ela se sentiu muito ofendida e quase perdeu o marido por achar que fora infiel, até descobrir que seu caso era um falso positivo por meio de outros dois exames feitos em laboratórios diferentes. 
Destarte, a presente pesquisa apresenta uma reflexão sobre humanização em saúde e a aplicação dos fundamentos da bioética no trato com os pacientes portadores de HIV/aids, e tenta fomentar a discussão se existem princípios da ética/bioética que podem (ou devem) ser aplicados na conduta dos profissionais de saúde, correlacionando com a política nacional da humanização do SUS.

Desta feita, percebe-se a necessidade em se pesquisar sobre o tema no intuito de inserir o conceito de humanização no cotidiano das unidades de saúde, o que, sobretudo, não é considerado uma tarefa fácil, visto que a melhoria do modelo de atenção requer mudanças do modelo de gestão.

Trata-se de um estudo do tipo bibliográfico. Após a definição do tema, foi feita uma busca em bases de dados virtuais em saúde, especificamente na Biblioteca Virtual de Saúde (BIREME). Foram utilizados os descritores: humanização, saúde, ética, HIV.

O passo seguinte foi uma leitura exploratória das publicações apresentadas no Sistema Latino-Americano e do Caribe de Informação em Ciências da Saúde LILACS, National Library of Medicine (MEDLINE) e Bancos de Dados em Enfermagem (BDENF), Scientific Electronic Library online (Scielo), no período de 2002 a março de 2013, caracterizando, assim, o estudo retrospectivo, em todos os idiomas, buscando as fontes virtuais, os anos, os periódicos, os idiomas, os métodos e os resultados comuns.

\section{Da Política Nacional de Humanização do SUS}

Prefacialmente, cabe registrar o entendimento acerca da proposta de humanização, que é apresentada como um conjunto de princípios e diretrizes que afirma a valorização dos diferentes sujeitos implicados no processo de produção de saúde (usuários, trabalhadores e gestores); o fomento da autonomia e do protagonismo desses sujeitos; o aumento do grau de corresponsabilidade na produção de saúde e de sujeitos; o estabelecimento de vínculos solidários e de participação coletiva no processo de gestão; a identificação das necessidades sociais de saúde, dos usuários e dos trabalhadores; e o compromisso com a ambiência, com a melhoria das condições de trabalho e de atendimento (Deslandes; Araújo, 2009).

Com a criação do Sistema Único de Saúde (Lei Orgânica da Saúde no 8.080/1990), é firmado o compromisso de cumprir os objetivos de promoção, proteção e recuperação da saúde, a organização e o funcionamento dos serviços com base nos princípios de universalidade, descentralização, integralidade, equidade e do controle social com a participação da comunidade (Lei no 8.142/1990).

A proposta da Política Nacional de Humanização (PNH) coincide com os próprios princípios do SUS, enfatizando a necessidade de assegurar atenção integral 
à população e estratégias de ampliar a condição de direitos e de cidadania das pessoas, segundo leciona Santos Filho (2007).

Em 1995, foi emitido importante documento - a Cartilha dos Direitos do Paciente - pelo Conselho de Saúde do Estado de São Paulo, que expressa, entre outros, o direito dos usuários a ter um atendimento digno, atencioso e respeitoso; a ser identificado e tratado pelo seu nome ou sobrenome; a não ser identificado ou tratado por números, códigos ou de modo genérico, desrespeitoso, ou preconceituoso; a ter resguardado o segredo sobre seus dados pessoais, através da manutenção do sigilo profissional, desde que não acarrete riscos a terceiros ou à saúde pública; a poder identificar as pessoas responsáveis, direta e indiretamente, por sua assistência; receber informações claras, objetivas e compreensíveis sobre hipóteses diagnósticas, diagnósticos realizados, exames solicitados e ações terapêuticas; a consentir ou recusar, de forma livre, voluntária e esclarecida, com adequada informação, procedimentos diagnósticos ou terapêuticos a serem nele realizados; a acessar, a qualquer momento, o seu prontuário médico (art. 2ํㅡ, incisos I a VIII), consoante informa Fortes (2004).

Com o passar dos anos, devido à necessidade de mudança nas políticas de saúde, muitos projetos de humanização vêm sendo desenvolvidos, conforme se depreende da leitura do artigo de Mota; Martins e Veras (2006), em áreas específicas da assistência - por exemplo, na saúde da mulher, na humanização do parto e na saúde da criança com o projeto mãe-canguru, para recém-nascidos de baixo peso, atendimento aos portadores de HIV/aids etc.

Como uma estratégia de qualificação da atenção e gestão do trabalho, a humanização almeja o alcance dos usuários e também a valorização dos trabalhadores; seus indicadores devem, portanto, refletir as transformações no âmbito da produção dos serviços (mudanças nos processos, organização, resolubilidade e qualidade) e da produção de sujeitos (mobilização, crescimento, autonomia dos trabalhadores e usuários) (Brasil, 2004).

O tema da humanização compreende um conjunto de elementos que remetem à pessoa humana, como sujeito do processo de humanização. A humanização não é imposta ou obrigatória, não é aplicada em prática após uma reunião de diretoria. $\mathrm{Na}$ prática humanitária, o profissional se permite ser humano, sentir-se em relação com o outro, também ser humano, manifestar sua sensibilidade, criar empatia, estabelecer relação sujeito/sujeito e, desta forma, tornar a ação/intervenção um ato completo.

Os profissionais da saúde devem ser valorizados e reconhecidos pelas suas habilidades, competências desenvolvidas no dia a dia no âmbito das instituições de saúde, devem honrar sua profissão, profissão esta voltada para o bem estar e a recuperação da saúde do indivíduo. Este profissional também tem que ser visto como um ser humano, passível de instabilidades emocionais e infelizmente também 
exposto ao imperdoável ato de errar, pois o cuidador é, portanto, gente cuidando de gente, e cada um com sua singularidade.

Os gestores do âmbito da saúde devem inserir em suas instituições, programas voltados a cuidar de quem cuida, ou seja, cuidar também de seus profissionais, envolver especialistas como fisioterapeutas, psicólogos, educadores físicos e outros, para apoiar e manter a saúde de suas equipes.

É necessária reação de todos os envolvidos no âmbito da saúde para gerarmos as ações, e somente com amor, respeito, motivação, dignidade e ética atingiremos as metas almejadas e uma assistência ao cuidar, qualificada e humanizada.

\section{Da aplicação dos princípios da Ética e da Bioética no tratamento dos pacientes do SUS portadores do HIV e doentes de aids}

No intuito de fornecer aos pacientes do SUS, portadores de HIV/aids, um tratamento pautado na ética e na bioética, a PNH se norteia em princípios, quais sejam:

- Valorização da dimensão subjetiva e social em todas as práticas de atenção e gestão no SUS, fortalecendo o compromisso com os direitos do cidadão, destacandose o respeito às questões de gênero, etnia, raça, orientação sexual e às populações específicas (índios, quilombolas, ribeirinhos, assentados etc.);

- Fortalecimento de trabalho em equipe multiprofissional, fomentando a transversalidade e a grupalidade;

- Apoio à construção de redes cooperativas, solidárias e comprometidas com a produção de saúde e com a produção de sujeitos;

- Construção de autonomia e protagonismo dos sujeitos e coletivos implicados na rede do SUS;

- Corresponsabilidade desses sujeitos nos processos de gestão e atenção;

- Fortalecimento do controle social com caráter participativo em todas as instâncias gestoras do SUS;

- Compromisso com a democratização das relações de trabalho e valorização dos profissionais de saúde, estimulando processos de educação permanente (Brasil, 2004).

Nesse sentido, a fim de construir respostas políticas à epidemia do HIV/aids, a Política Nacional do programa brasileiro compreende três eixos principais, e esperase que funcionem de forma integrada e com base nos princípios do SUS. 
Todos os eixos explicitam um referencial teórico e ético que dialoga com conceitos tais como: promoção à saúde e prevenção, direitos humanos, controle social e vulnerabilidade.

Conforme ensinam Sousa, Lima e Munari (2008), as DSTs implicam em práticas de foro íntimo e são decorrentes do exercício da sexualidade. Sendo assim, os profissionais têm a oportunidade ímpar de conversar sobre aspectos da intimidade da vida da pessoa em atendimento e, assim, necessitam ter clareza a respeito dos valores sexuais do paciente, assim como de seus próprios.

Atitudes de preconceito, juízos de valor e imposição de condutas deverão ser evitadas e, apesar das eventuais diferenças, o diálogo será garantido. Caso contrário, consequências negativas poderão incidir, por exemplo, supressão de informações necessárias para a realização do diagnóstico ou despreocupação quanto à real gravidade da doença ou, por outro lado, superdimensioná-la, acarretando, desse modo, angústias dispensáveis ou até mesmo desajustes conjugais (Brasil, 1999).

Mister esclarecer que o indivíduo deverá ser visto como um todo, constituído por sentimentos, crenças, valores, aspectos esses determinantes das práticas de risco e atitudes diante do tratamento prescrito. Seu comportamento orgânico também não se restringe aos órgãos genitais. Lembremos que outras doenças (ex.: diabetes, dermatoses, imunodeficiências etc.), o estado nutricional e o uso de medicamentos podem interferir tanto no diagnóstico como no tratamento das DSTs (Casate; Corrêa, 2005).

No atendimento motivado por DST, os profissionais de saúde deverão incluir o exame clínico-genital minucioso, que contemple a busca de outras DSTs, educação para redução de riscos, orientação sobre cuidados higiênicos, oferecimento do teste de sífilis, hepatite B e anti-HIV, aconselhamento, estímulo à adesão ao tratamento, promoção do uso de preservativos, busca de parceiros sexuais e notificação do caso.

Ressalta-se que a aplicação de princípios, em casos particulares no campo da saúde, refere-se, primeiramente, à realização de um valor, ou, numa perspectiva habermasiana (1989), na explicitação de um ponto de vista moral. Gracia (2005) afirma que não é o valor em si que está em questão quando temos um conflito, uma vez que o valor terá sempre características positivas, digno de ser respeitado, preservado ou realizado. O conflito está no ato ou ação que é a escolha para a realização de um determinado "bem" pré-estabelecido e reconhecido socialmente.

O movimento para a concretização desse bem (socialmente reconhecido e validado) pode, por vezes, denotar abrir mão de outro valor também reconhecido. Nesse caso, ressalta-se a importância para a necessidade humana de "realizar valores" (Gracia, 2005), embora reconheça que haja abordes estabelecidos pela vida prática na busca dessa efetivação. Nesse sentido, restará caracterizado o embate, em um primeiro momento, como um movimento na busca da melhor solução, ou 
aquela que possa representar a decisão que melhor atenda a realização e/ou preservação de valores submergidos em circunstâncias práticas.

A bioética, como tratada por Gracia (2005), pode ser compreendida como uma bioética deliberativa, apoiando-se na deliberação, na hermenêutica, na responsabilidade e na prudência. Utilizam-se três categorias analíticas interrelacionadas: fatos, valores e deveres. A experiência moral é ponto de partida da explicação e constitui-se como um fato nos termos fenomenológicos. A experiência moral é a experiência da obrigação, que configura o fato, o fato moral de onde partem as explicações (as teorias éticas). A experiência moral se expressa no aspecto de que todo ser humano faz juízos dessa ordem, sente que há coisas que deve fazer e outras que não deve fazer, e pede contas a si próprio e aos demais do que vai fazer e do que fez.

O agir moral, nesses termos, envolve três faculdades da inteligência humana: cognitiva (fatos); emocional (valores); volitiva (deveres). Diante dos fatos, o momento valorativo reclama o volitivo, isto é, o fato interpela o sujeito quanto ao reconhecimento de valores e demanda sua disposição para realizá-los em ações práticas (Zoboli, 2010).

Oportuno mencionar que profissionais de saúde, como sujeitos morais, apoiam suas ações em códigos éticos válidos socialmente. Tecem opiniões, reproduzem avaliações acerca de "modos de vida", construindo, na prática, ações que podem ser tomadas como técnica moral dependente, conforme nomeado por Schraiber (2008) ao investigar o trabalho do médico na contemporaneidade. Isto é, nas ações que articulam os processos de trabalho, em que pese operarem-se técnicas aparentemente bem definidas por meio de critérios clínicos protocolados, cada profissional procede a julgamentos que levam em conta a situação particular, o que denota uma dada autonomia a esse trabalho e sua articulação entre a produção de respostas às necessidades sociais.

Se examinarmos os casos identificados como problemáticos no cotidiano da atenção às pessoas vivendo com HIV/aids, será possível identificar posicionamentos, de profissionais e usuários, acerca de ideários e modos de vida que tomamos como adequados para nós e para o outro na relação assistencial, ou ainda mantendo uma centralidade na predominância da necessidade de controlar a doença (Oliveira, 2009). Para além dos discursos apoiados em lógicas técnicas ou de controle da doença, há aspectos presentes nas decisões que temos de tomar que são inerentes ao mundo da vida e que nos dão conta de como a normatividade social (nossos julgamentos sobre o que é correto fazer em nossas relações com o outro) penetra a aparentemente neutra esfera da técnica. Ao compreendermos o encontro profissionalusuário como um diálogo, em um mundo compartilhado no qual a situação existencial de cada uma das partes (seus projetos de felicidade) é a fonte primeira do sentido concreto da ação técnica, então, também poderemos compreender as diferentes 
situações problemáticas como o embate entre os diversos "dever ser" que orientam as expectativas e ações desses sujeitos. E talvez, se formos bem-sucedidos, poderemos reconhecer, também, as estratégias mais prudentes para sua resolução.

Em síntese, para a compreensão e enfrentamento dos conflitos encontrados no cotidiano da atenção às pessoas vivendo com HIV/aids (Oliveira, 2009), como de outros temas complexos e delicados na prática de saúde, defende-se, como perspectiva teórica, a assunção do caráter eminentemente relacional e comunicacional do trabalho em saúde, interpretando-o como um diálogo em curso e aberto aos desencontros e embates aí experimentados. Quando esses desencontros localizam-se no âmbito moral, a deliberação, ou, a bioética deliberativa, apresenta-se como uma sistemática para o confronto dialógico entre valores em conflito.

A própria ideia de "valor" concebe-se na perspectiva de um horizonte ético, que somente faz sentido no convívio com o outro, no interesse em compatibilizar finalidades e meios de uma vida que só é possível de ser vivida em comum (Ayres, 2009).

Ao compreendermos o encontro profissional-usuário como um diálogo, em um mundo compartilhado no qual a situação existencial de cada uma das partes (seus projetos de felicidade) é a fonte primeira do sentido concreto da ação técnica, então, também poderemos compreender as diferentes situações problemáticas como 0 embate entre os diversos "dever ser" que orientam as expectativas e ações desses sujeitos. E talvez, se formos bem-sucedidos, poderemos reconhecer, também, as estratégias mais prudentes para sua resolução.

As proposições da ética discursiva habermasiana possibilitam reconhecer as posições assumidas, pelos sujeitos, no plano da moral, como uma racionalidade que busca validar-se intersubjetivamente a cada situação concreta que coloca em cheque algum pressuposto do mundo vivido. Trouxemos, como exemplo analítico, partindo desse quadro, a mudança nos discursos políticos e sociais para aids, que acabaram por configurar sua política de enfrentamento. Essa construção teórica nos apresenta uma ética da razão prática, que pode ser reconhecida nas proposições concretas em que aparecem, por exemplo, nas intervenções em saúde, os ideais do que é "bom e justo" fazer, tanto para o indivíduo como para todos os membros de uma comunidade ou sociedade. Essa ética implica não só o autoconhecimento e a autocompreensão, como também certos ideais, certos valores socialmente validados (Habermas, 1989).

Por fim, conclui-se que a humanização entrelaçada com a bioética é um processo amplo, demorado e complexo, ao qual se oferecem resistências, pois envolve mudanças de comportamento, que sempre despertam insegurança. Ela pode ser comparada a uma planta, que deve ser regada diariamente para dar frutos e não morrer. Em uma instituição de saúde, todo o profissional, de cada equipe, tem seu processo singular de humanização. E se não for singular, não será de humanização. 


\section{Conclusão}

Uma política pública expressa o conjunto das diretrizes e referenciais éticolegais adotados pelo Estado para fazer frente a um problema e/ou a uma demanda que a sociedade apresenta. Cabe ao Estado definir seu caráter, suas responsabilidades, seu plano de ação e programas, a fim de buscar o equacionamento dessa demanda.

Nota-se que a PNH não foi apenas uma proposta, mas sim uma experiência que está sendo vivenciada e explorada desde sua implantação para melhoria da qualidade da assistência à saúde no Brasil. Destarte, pode-se afirmar que, em relação às práticas relacionadas ao SUS, ainda há muito que se desconstruir e construir, uma vez que humanizar é, mormente, criar condições para que a produção da saúde se dê de maneira eficiente e eficaz.

Noutra banda, eficiência e eficácia em um sistema onde há tantas crises são obtidas apenas quando há espaço para o diálogo entre os sujeitos, quando se afiança o direito de expressão independente de posições hierárquicas. Talvez, nesse ponto se estabeleça o liame mais crucial a ser combalido.

A efetividade da ação em DST/HIV e aids decorre fundamentalmente do reconhecimento de que desde o primeiro contato, tanto da equipe da unidade básica de saúde quanto da de saúde da família, na relação profissional de saúde $\mathrm{x}$ usuário do serviço, o usuário deve ser visto de forma integral, não podendo essa percepção estar dissociada de seu contexto sociocultural, incluindo, logicamente, a sua sexualidade, já que essa, dentre outras coisas, confere matizes diversos aos seus gestos, atitudes e decisões ao longo de toda a sua vida que, evidentemente, interferem muito em seu estado de saúde.

Intervir nas questões de saúde relacionadas às DST e aids nos coloca diante de desafios, cuja complexidade e amplitude estão relacionados, muitas vezes, aos nossos valores morais e conceitos diversos de vida, mas a promoção da saúde deve estar posicionada sempre acima dos julgamentos sobre os comportamentos dos indivíduos, considerando sua ocupação profissional, suas relações amorosas, sua orientação sexual ou outras singularidades, sob risco de se comprometer fortemente o princípio de universalidade e integralidade do SUS.

Todas as oportunidades devem ser aproveitadas pela equipe de saúde para acolher de forma humanizada o usuário, entendendo as dificuldades de exposição das questões sexuais que, evidentemente, são questões íntimas, procurando detectar e atender suas necessidades e realizando aconselhamento para que os indivíduos tenham segurança da privacidade e sigilo, saibam da existência de casos 
assintomáticos ou pouco sintomáticos, também suscetíveis a graves complicações, para maior adesão ao tratamento, etc.

Importa esclarecer que a simples atitude de receber bem o cliente/paciente, escutando-o, configura o primeiro passo a ser dado em prol de uma assistência integral e humanizada ao paciente.

Contudo, é importante ressaltar que, muitas vezes, devido à sobrecarga imposta pelo cotidiano do trabalho, o atendimento configura-se mecanizado e tecnicista, não reflexivo, deixando de humanizar o cuidado justamente por entender que em si o cuidado deve ser humanizado.

Sendo assim, vale observar que o esforço, muitas vezes, não resulta em alteração nas práticas cotidianas dos serviços de saúde, na melhora das condições de trabalho dos profissionais de saúde e na melhoria da qualidade de vida dos usuários.

Por fim, esse estudo permitiu conceber a humanização não como utopia ou como tema desgastante que vem sendo repetido há vários anos, mas como um ideal admissível. Uma boa ideia a se colocar em prática para que se evitasse a desumanização no momento da notícia ao paciente sobre a sua infecção com o vírus HIV/aids seria a criação de uma equipe multidisciplinar composta por médico, psicólogo e assistente social, para que apresentassem essa notícia de forma humana, com urbanidade, amparassem o paciente e o informassem sobre as suas opções de tratamento e encaminhamento para um centro de referência, bem como, se possível, resguardada a confidencialidade, documentassem esse evento com filmagem, para evitar futuros conflitos judiciais baseados em notícia de grosseria ou tratamento degradante e desumano nesse momento importante na vida do infectado. Desta feita, vale persistir na exploração do assunto, abordá-lo dentro e fora das instituições de saúde, a fim de que a sociedade em geral participe e opine, e experiências de sucesso sejam compartilhadas, sem a pretensão de esgotar 0 assunto, dada a complexidade e peculiaridades de cada ser humano.

\section{Referências}

AYRES, J.R.C.M. Cuidado: trabalho e interação nas práticas de saúde. Rio de Janeiro: Cepes, IMS/UERJ, Abrasco, 2009.

BRASIL. Constituição (1988). Constituição da República Federativa do Brasil: promulgada em 5 de outubro de 1988. Diário Oficial da União, Brasília, 05 out. 1988. Disponível em: http://www.planalto.gov.br/ccivil 03/constituicao/constitui\%C3\%A7ao.htm

Acesso em: 3 mar. 2013.

- Ministério da Saúde. Manual de orientação básica para a equipe de enfermagem: prevenção do HIV e assistência a pessoas portadoras do HIV e de aids. Brasília : Ministério da Saúde; 1999. 
Humaniza SUS. Política Nacional de Humanização. Brasília : Ministério da Saúde, 2004.

CASATE, J. C.; CORRÊA, A. K. Humanização do atendimento em saúde: conhecimento veiculado na literatura brasileira de enfermagem. Revista LatinoAmericana de Enfermagem, 13(1):105-11, jan/fev. 2005. Disponível em: http://www.scielo.br/pdf/rlae/v13n1/v13n1a17.pdf Acesso em 6 mar. 2013.

DESLANDES, S. F.; ARAUJO, R M. M. de. Processo comunicativo e humanização em saúde. Interface - Comunicação, Saúde, Educação, Botucatu, 13(supl.1):.641-9, 2009. Disponível em: http://www.scielo.br/scielo.php?pid=S141432832009000500015\&script=sci arttext . Acesso em: 3 mar. 2013.

FORTES, P A C de. Ética, direitos dos usuários e políticas de humanização da atenção à saúde. Saúde e Sociedade, 13(3):30-35, set/dez. 2004. Disponível em: http://www.scielo.br/pdf/sausoc/v13n3/04.pdf . Acesso em 3 mar. 2013.

GRACIA, D. Semiología de los conflictos morales en bioética. [Conferência apresentada no VI Congresso Brasileiro de Bioética em Foz do Iguaçu - PR]. 2005; Mimeo.

HABERMAS J. Comentários à ética do discurso. Lisboa: Instituto Piaget, 1999.

1989.

Consciência moral e agir comunicativo. Rio de Janeiro: Tempo Brasileiro,

MOTA, R.A.; MARTINS, C.G.M.; VÉRAS, R. M. de. Papel dos profissionais de saúde na política de humanização hospitalar. Psicologia em Estudo, Maringá, 11(2):323-330, maio/ago. 2006. Disponível em: http://www.scielo.br/pdf/pe/v11n2/v11n2a10.pdf . Acesso em: 3 mar. 2013.

OLIVEIRA, L.A. et al. Humanização e cuidado: a experiência da equipe de um serviço de DST/Aids no município de São Paulo. In: AYRES, J.R.C.M. (Org.). Cuidado: trabalho e interação nas práticas de saúde. Rio de Janeiro: Cepes, IMS/UERJ, Abrasco, 2009. p. 211-32.

SANTOS FILHO, S. B. Perspectivas da avaliação na Política Nacional de Humanização em Saúde: aspectos conceituais e metodológicos. Ciência \& Saúde Coletiva, 12(4):999-1010, 2007.2 Disponível em: http://www.scielo.br/scielo.php?pid=S1413-81232007000400021\&script=sci arttext Acesso em 3 mar. 2013.

SCHRAIBER, L.B. O médico e suas interações: a crise dos vínculos de confiança. São Paulo: Hucitec, 2008.

SOUZA, J. C.; LIMA, J. O. R.; MUNARI, D. B. Ensino do cuidado humanizado: Evolução e tendência na produção científica. Revista Brasileira de Enfermagem, 61(6):878-82, nov/dez. $2008 . \quad$ Disponível em: http://www.scielo.br/pdf/reben/v61n6/a14v61n6.pdf . Acesso em 6 mar. 2013.

ZOBOLI, E.L.C.T. Deliberação: leque de possibilidades para compreender os conflitos de valores na prática clínica da atenção básica. 2010. Tese (Livre-Docência) Faculdade de Saúde Pública, Universidade de São Paulo, São Paulo. 2010. 